Былинская Наталья

кандидат психологических наук, доцент, заведующий кафедрой психологии

Брестского государственного университета им. А.С. Пушкина, г. Брест (Республика Беларусь) orcid.org/0000-0002-2545-5592

DOI https://doi.org/10.35619/prap_rv.vi14.148

\title{
СОЦИАЛЬНЫЕ ПРЕДСТАВЛЕНИЯ ОБ ОТЦОВСТВЕ У МУЖЧИН И ЖЕНЩИН, СОСТОЯЩИХ И НЕ СОСТОЯЩИХ В БРАКЕ
}

\begin{abstract}
Аннотация. В настоящей статье обсуждается феномен «отиовство» в контексте научных и житейских, обыденных представлений, изложены результаты изучения структуры и содержания представлений об отцовстве, существующчих в сознании мужчин и женщин. Сравнительный анализ структуры и содержания представлений показал, что в содержании представлений об отцовстве у мужчин и женщин, состоящих и не состоящих в браке, есть общие и специфические дескрипторы. Общие свидетельствуют о единстве понимания, а специфические указывают на различие в представлениях об отиовстве: они в значительной мере уникальны и индивидуальны для каждого человека. Установлено, что структура и содержание представлений об отиовстве имеет качественные и количественные особенности, характерные для представителей разного пола. По структуре и содержанию представления об отцовстве у мужчин, состоящих и не состоящих в браке, являются довольно простыми, в то время как у женщин со вступлением в брак, представления об отцуовттве усложняются, становятся глубже и чувственнее.
\end{abstract}

Ключевые слова: отеи, отиовство, семья, сочиальные представления, обыденное сознание, факторный анализ, фактор, конструкт.

Постановка проблемы. На протяжении многих веков обществом за мужчиной закрепились и стали традиционными функции материального обеспечения семьи и защиты женщин и детей. В этом контексте отец выполняет роль главы семейства, принимает важные решения, советует и руководит процессами, происходящими в семье. В настоящее время обращает на себя внимание «новый образ мужчины», который во многом противоположен традиционному. Появление новой модели отцовства связывают с демократическими, гуманистическими тенденциями в обществе, равноправием супругов в распределении прав и обязанностей в семье. При этом успешное отцовство заключается в осознанной подготовке мужчины к выполнению отцовской роли, которая заключается в активном участии мужчины в воспитании детей, искреннем проявлении интереса к успехам ребенка и взаимодействии с ним (Борисенко, 2007; Кон, 2003; Окулич, 2015; Павлов, 2014). Однако современные социальные стереотипы отцовства опосредованы довольно разнообразной и противоречивой системой представлений, существующих в сознании, как мужчин, так и женщин о том, что именно должен делать отец. При этом представления об отцовстве у мужчин и женщин формируются не на основе научных знаний, а на основе обыденного житейского опыта, откуда люди черпают ожидания и представления о данном феномене. Формирование и изменение социальных представлений может рассматриваться в аспекте гендерной специфики и динамики организации знаний у взрослых людей в повседневной коммуникации (Московичи, 2007). Следовательно, исследование представлений об отцовстве позволит описать специфику структуры и содержания этих представлений, опосредующих характер взаимодействия мужчины с ребенком и внутрисемейные отношения в целом.

Анализ исследований по проблеме. Современные исследования, касающиеся личности отца, сосредотачиваются на проблемах мотивации родительства, ценностной ориентации мужчины и его психологической готовности к выполнению отцовской роли. Психологическая готовность к отцовству определяется сформированностью всех аспектов личности, 
предполагающих выполнение возложенных обязанностей и принятых обязательств; знаний функций отца в семье и его роли в воспитании ребенка; оценки готовности принять на себя ответственность за жизнь и благополучие ребенка. В меньшей степени в литературе представлены исследования, посвященные содержанию представлений об отцовстве у самих мужчин и женщин. Изучение представлений об отцовстве нами видится довольно значимым, поскольку их структура и содержание опосредует взаимодействия.

Целью настоящего исследования являлось выявление структуры и содержания представлений об отцовстве у мужчин и женщин, состоящих и не состоящих в браке.

Изложение основного материала исследования. В настоящем исследовании приняли участие :100 мужчин в возрасте от 18 до 25 лет (50 мужчин, состоящих в браке, и 50 мужчин, не состоящих в браке) и 100 женщин в возрасте от 18 до 25 лет (50 женщин, состоящих в браке, и 50 женщин, не состоящих в браке). Исследование носило индивидуальный характер и осуществлялось методом свободного описания. Респондентам предлагалось анонимно и добровольно написать сочинение: «Что в Вашем понимании является отцовством?»

В качестве примеров, представим несколько вариантов сочинений.

- «Отцовство - это новый период в жизни, связанный с возложением на себя обязательств по воспитанию детей, содержанию семьи, принятию важных и ответственных решений как главы семьи, учитывая мнение каждого члена семьи. Это ответственность за поступки детей. Быть отцов - значит быть примером для всей семьи, защищать интересы своей семьи в любых ситуациях, следить за здоровьем всей семьи, стараться уделять внимание в равной степени каждому члену семьи» (мужчина, 24 года, женат).

- «Отцовство - это ответственность и забота, радость и расстройства, надежды и разочарования, заработок и расходы, гордость и нервность, воспитание и ремень, продолжение рода и половое бессилие» (мужчина, 21 год, холост).

- «Отцовство - это забота о семье, любовь, нежность к детям, жене, умение их любить. Отцовство затрагивает чувство долга перед близкими людьми и обществом, трудолюбие, силу, стойкость, упорство и мужество, доверие к своему духовному «Я», чувство собственного достоинства и ощущение личной ответственности. Это те качества, которые мать не сможет воспитать в ребенке при всем своем желании, так как эта роль предназначена отцу, человеку на которого можно положиться в любой ситуации, любящему и уважительно относящемуся к своей семье. Отцу принадлежит огромная роль в воспитании ребенка. Отцовство - высший уровень развития личности мужчины» (женщина, 23 года, замужем).

- «Настоящий отец должен быть любящим и заботливым. Он должен воспитывать ребенка, подавая хороший пример, так как дети очень склонны к подражанию. Также хороший отец должен обладать чувством ответственности и долга, способностью обеспечить защиту и безопасность семьи, финансами. У отца должно сформироваться желание ухаживать за ребенком. Также должна быть своя твердая жизненная позиция. Если у мужчины нет почвы под ногами, то он сам требует поддержки и ориентиров, его трудно будет назвать хорошим отцом» (женщина, 19 лет, не замужем).

Данные обрабатывались посредством контент-анализа. Затем на основе индивидуальных протоколов строились обобщенные матрицы данных. Из матрицы были исключены единичные ответы, которые принято рассматривать как результат индивидуальной вариации. Исходная матрица обрабатывалась посредством факторного анализа, сущность которого заключается в нахождении таких комплексных факторов, которые как можно более полно объясняют наблюдаемые связи между переменными, имеющимися в наличии, методом главных компонент с подпрограммой варимакс-вращения. Полученные в итоге факторы являются отражением категорий, образующих содержание социальных представлений мужчин и женщин, состоящих и не состоящих в браке. Для дальнейшего обсуждения представлены только те факторы, которые являются наиболее значимыми по своей валентности для респондентов. Процент общей дисперсии обозначает субъективную значимость фактора, а представленные числа - нагрузку качеств, образующих данную категорию.

Социальные представления об отцовстве у мужчин, состоящих в браке 
Первыци фактор (7\% общей дисперсии) образован шкалами: ответственность (0.856),честность (0.705), уверенность (0.506), надежность (0.477). В содержание данного конструкта включены шкалы, которые принято относить к мужским, а именно сила, ответственность, целеустремленность, надежность, уверенность. Мужчина в сложных жизненных ситуациях должен уметь принимать на себя ответственность, самостоятельно принимать сложные решения любых проблем, не паниковать, а брать ситуацию под свой контроль, доводить до конца начатое дело. Эту категорию можно обозначить «Мужские качества».

Второй фактор (6,3\% общей дисперсии) содержит шкалы: радость за созданную новую жизнь (0.807), любовь (0.725), гордость (0.467). В содержание этого фактора включен эмоциональный компонент оценочного отношения к отцовству: радость, чувство удовлетворенности, любовь, благодарность и гордость за созданную новую жизнь, за продолжение рода. Данный фактор можно назвать «Гордость за продолжение рода».

Третий фактор (6,1\% общей дисперсии) включает дескрипторы: материальная готовность (0.814), духовная готовность (0.711). Содержание этой категории свидетельствует о готовности выполнения семейных обязанностей, что от мужчины требует затрат материальных и личностных ресурсов. Этот фактор можно назвать «Готовность к семейной жизни».

Четвертый фактор (5,9\% общей дисперсии) включает шкалы-характеристики: игры $c$ детьми (0.737), совместный отдых (0.719), сплочение семьи (0.424). Эту категорию обозначим «Детско-родительские отношения», проявляющихся в совместной деятельности родителей и детей, а также в необходимости со стороны родителей высокой коммуникативной компетенции. В отношениях должно присутствовать открытое личностное общение между родителем и ребенком, цель которого - полное раскрытие и развитие индивидуальных особенностей, потенциальных возможностей, как ребенка, так и взрослого.

Пятый фактор (5,8\% общей дисперсии) образован шкалами: воспитание (0.827), пример для подражания (0.478), забота (0.433). Данную категорию можно назвать «Воспитание детей». По мнению респондентов, отец принимает активное участие в воспитании ребенка, проявляя, тем самым, заботу о нем. Целью воспитания является формирование и развитие личности с теми качествами, которые необходимы для жизни в обществе, отец, при этом, является примером для подражания.

\section{Социальные представления об отцовстве у мужчин, не состоящих в браке}

Первыци фактор (9,1\% общей дисперсии) включает шкалы: семья (0.842), дети (0.787), забота (0.775), воспитание (0.668), любовь (0.655), продолжение рода (0.582). В содержание данного конструкта включены шкалы, характеризующие основные функции семьи, такие как репродуктивная (биологическое воспроизводство и сохранение потомства, продолжение рода), воспитательная (семья формирует личность ребенка, оказывает систематическое воспитательное воздействие на каждого члена в течение всей жизни), коммуникативная (организация внутрисемейного общения, досуга и отдыха). Эту категорию можно обозначить «Функции семьи».

Второй фактор (7\% общей дисперсии) содержит дескрипторы: хозяйственность (0.838), пример для подражания (0.721), защита (0.577). Данную категорию можно определить как «Глава семьи». Отец, как глава семьи, берет на себя ответственность за принятие решений в сложных, проблемных ситуациях. Кроме того, мужчина отвечает за соблюдение правил, принятых в семье.

Третий фактор (5,4\% общей дисперсии) образован шкалами: нервность (0.881), переживание (0.698), ремень (0.616). Содержание этого фактора свидетельствует об ожидании мужчинами трудностей в общении с детьми и их воспитании. Некоторые родители воспитывают своих детей методом запретов и наказаний, не вдаваясь в объяснения. Этот стиль требует минимального времени, выглядит просто, срабатывает быстро. Его часто используют те мамы и папы, которые не любят, чтобы ребенок «мешал взрослым». И при этом они невольно пересекают опасную грань. Это свидетельствует о том, что родители, а в частности мужчины, в воспитании детей должны играть основную роль. Этот фактор можно назвать «Воспитание детей».

Четвертый фактор (5,3\% общей дисперсии) включает: половое бессилие (0.804), деньги (0.585), работа (0.556). Содержание этого фактора констатирует значимость для современных мужчин карьеры и возможности достойного материального обеспечения семьи. Эту категорию можно обозначить «Заработок». 
Пятый фактор (5,1\% общей дисперсии) содержит шкалы: отношение (0.825), уважение (0.542), взаимопонимание (0.449). Эту категорию обозначим «Семейные отномения», при которых взаимопонимание проявляется тогда, когда супруги готовы слушать и понимать друг друга, принять и уважать точку зрения партнера. Это те связи между членами семьи, которые проявляются через характер и способы межличностного взаимодействия, через влияние членов семьи друг на друга при совместной деятельности и общении. Основой семейных отношений являются жизненные цели супругов, их установки, ожидания, нравственные нормы и ценности.

\section{Социальные представления об отцовстве у женщин, состоящих в браке}

Первый фактор (7,4\% общей дисперсии) содержит шкалы:доброта (0.774),защита (0.720), радость (0.616), уверенность (0.527). Данную категорию можно определить как «Эмоциональное благополучие», проявляющееся в уверенности в себе, чувстве защищенности, положительном самоощущении и жизненных успехах. Эмоциональное благополучие предусматривает удовлетворение потребности в общении, установлении доброжелательных взаимоотношений в семье. Оно во многом зависит от того, как складываются отношения человека с окружающими людьми. Для каждого важно иметь хороших и верных друзей, которые не только дарят радость общения, делая жизнь богаче и разнообразнее, но и могут выручить в трудных ситуациях. Эмоциональное благополучие способствует нормальному развитию личности, выработке положительных качеств, доброжелательного отношения к другим людям.

Второй фактор (6,7\% общей дисперсии) образован шкалами: умение любить (0.767), заботливость (0.763). Эту категорию обозначим «Любовь», которая предполагает заботу о близких, преодоление трудностей и конфликтов, прощение, доверие, посвящение себя их благополучию, принятие их такими, какими они и являются, без всяких условий.

Третий фактор (6\% общей дисперсии) включает дескрипторы: пример для подражания (0.842), материальная обеспеченность (0.699), справедливость (0.601). Этот фактор можно назвать «Воспитание детей», целью которого является формирование и развитие личности с теми качествами, которые необходимы для жизни в обществе. Отец, по мнению женщин, должен служить примером для подражания, быть справедливым человеком, который ведет себя по отношению к ребенку беспристрастно и справедливо. Эта категория уже встречалась в структуре представлений об отцовстве у мужчин, состоящих в браке.

Четвертый фактор (5,7\% общей дисперсии) содержит характеристики: взаимопонимание (0.798), верность (0.708), чуткость (0.513). Эту категорию можно обозначить как «Отношение к женщине», при котором взаимопонимание проявляется тогда, когда супруг готов слушать и понимать супругу, внимательно и уважительно относиться к ней, быть неизменным в своих обещаниях, словах, отношениях, в исполнении своих обязанностей.

Пятый фактор (5,6\% общей дисперсии) образован шкалами: честность (0.660), счастье (0.633), воспитанность (0.536). Данную категорию можно назвать «Морально-нравственные качества личности», по которым люди оценивают друг друга. Моральные качества определяют общественную направленность личности. Вступление общественного опыта нравственного поведения каждой личности - залог успеха в правильном воспитании детей. Ребенок не создает нового опыта нравственного поведения, а усваивает тот, который накоплен предыдущими поколениями.

Шестой фактор (5,5\% общей дисперсии) включает шкалы: поддержка (0.838), упорство (0.790), чувство долга (0.606), отзывчивость (0.528). Данную категорию можно обозначить как «Настойчивость», которая объясняется целеустремленностью и стремлением отца несмотря ни на что упорно и непрерывно продолжать свой путь, следуя принятому ранее решению. При этом он осознает и принимает те обязанности, которые взял на себя, вступая в определенные отношения с другими людьми, принимая, понимая и поддерживая других людей независимо от их сути, стиля жизни и характера.

Седьмой фактор (5,4\% общей дисперсии) образован шкалами: терпение (0.712), надежность (0.702), опора (0.505). Одним из основных чувств, необходимого для психического развития ребенка, является чувство защищенности, которое в младенчестве преимущественно связано с матерью. Когда ребенок начинает осваивать окружающий мир и осознает, что в мире много опасностей, с которыми женщине не справиться, в роли главного защитника начинает 
выступать отец. Недаром дети любят хвастаться друг перед другом отцовской силой: она как бы придает им силы, повышая их значимость в глазах окружающих. Данную категорию можно назвать «Надежный оплот».

Восьмой фактор (5,3\% общей дисперсии) включает: стойкость (0.754), трудолюбие (0.483), мужская сила (0.423). Содержание данного конструкта образуют шкалы, характеризующие совокупность черт характера, ожидаемых от мужчин. Эту категорию «Мужские качества» мы уже встречали в структуре представлений об отцовстве у мужчин, состоящих в браке.

Девятый фактор (5,3\% общей дисперсии) содержит шкалы: здоровый климат в семье (0.765), доверие (0.660). Содержание данной категории свидетельствует о том, что отношения в семье в первую очередь должны носить здоровый характер, т.е. быть доверительными, с проявлением взаимопонимания между членами семьи. Это в свою очередь создает благоприятную почву для правильного, гармоничного развития личности ребенка. Фактор «Семейныле отношения» был ранее зафиксирован в структуре представлений об отцовстве у мужчин, не состоящих в браке.

Социальные представления об отцовстве у женщин, не состоящих в браке

Первыц фактор (9,4\% общей дисперсии) образован шкалами: трудолюбие (0.822), стойкость (0.791), упорство (0.763), доверие (0.675), чувство долга (0.675), мужская сила (0.537). Этот ведущий по своей значимости фактор близок по содержанию с конструктом «Мужские качества», который мы уже встречали в структуре представлений об отцовстве у мужчин и женщин, состоящих в браке.

Второй фактор (5,4\% общей дисперсии) образован дескрипторами: защита (0.672), игры (0.668), ответственность (0.500), радость (0.421), нежность (0.414). Содержание данного конструкта свидетельствует о необходимости проявления со стороны родителей высокой коммуникативной компетенции, участия в совместной деятельности членов семьи, а также о возложенной на отца ответственности не только за себя, но и за своих детей. Эту категорию «Детско-родительские отношения» мы уже встречали в структуре представлений об отцовстве у мужчин, состоящих в браке.

Третий фактор (5,4\% общей дисперсии) включает шкалы: время (0.694), забота (0.618), поддержка (0.607), тревога за неудачи (569). Содержание данной категории свидетельствует о необходимости проявлять заботу к ребенку, поддерживать его во всех начинаниях, беспокоится по поводу возможных неудач. Категорию можно назвать «Воспитание детей».

Четвертый фактор (5,3\% общей дисперсии) включает: честность (0.836), справедливость (0.610), терпимость (0.581). В содержание данного конструкта включены шкалы, относящиеся к морально-нравственным характеристикам личности. Ранее эта категория была зафиксирована как «Морально-нравственные качества личности» в структуре представлений об отцовстве у мужчин и женщин, состоящих в браке.

Пятый фактор (5\% общей дисперсии) образован дескрипторами: жизненный onыm (0.839), надежное плечо (0.639). Содержание выделенной категории свидетельствует о том, что отец является надежной опорой и обеспечивает защиту семьи. Эта категория ранее встречалась в структуре представлений об отцовстве у женщин, состоящих в браке, и была обозначена как «Надежный оплот».

Выводы по исследованию. Результаты факторизации данных показали, что по количеству зафиксированных факторов-категорий структура представлений об отцовстве у мужчин, состоящих в браке и не состоящих в браке, а также у женщин, не состоящих в браке, образована пятью ортогональными (независимыми) категориями; у женщин, состоящих в браке, - девятью ортогональными факторами. По мнению Андреевой (2001) количество категорий свидетельствует о когнитивной сложности или простоте представлений субъектов взаимодействия. В содержании представлений об отцовстве у мужчин и женщин, состоящих и не состоящих в браке, есть общие и специфические дескрипторы. Общие свидетельствуют о единстве понимания, а специфические указывают на различие в представлениях об отцовстве: они в значительной мере уникальны и индивидуальны для каждого человека. 
У мужчин, состоящих и не состоящих в браке, общим из пяти является только один фактор («Воспитание детей»). Это свидетельствует о том, что представления об отцовстве у мужчин, состоящих в браке, и мужчин, не состоящих в браке, отличаются по своему содержанию. По мнению мужчин, состоящих в браке, отец принимает участие в уходе и воспитании ребенка, проявляет к нему заботу, старается вступать в эмоциональный контакт с ребенком, общается с ним. Мужчины также стараются проявлять мужские качества, возлагая на себя ответственность не только за себя, но и за своих близких. По мнению мужчин, не состоящих в браке, отец как глава семьи в первую очередь обязан обеспечить защиту своим близким и создать по возможности достойную материальную базу для проживания. Погрузившись в обеспечение семьи всем необходимым, отец не уделяет должного внимания детям, оставаясь в стороне от их жизни. Эта категория мужчин с осторожностью относится к функции воспитания детей, ожидая трудностей при взаимодействии с ребенком. Процесс воспитания отцами воспринимается в большей степени как наставничество. В детях отец видит возможность самоактуализации, и в силу этого, возлагает на них определенные ожидания в отношении достижений, карьеры, результатов. В ребенке для отца воплощена возможность продолжения рода.

У женщин, состоящих и не состоящих в браке, общими являются четыре фактора («Мужские качества», «Воспитание детей», «Морально-нравственные качества личности», «Надежный оплот»). При этом женщины, состоящие в браке, являются более когнитивно сложными, нежели женщины, не состоящие в браке, поскольку в структуру их представлений кроме общих конструктов включено пять специфических категорий, содержание которых говорит о необходимости присутствия в семье чуткого отношения к женщине, как к матери ребенка, а также наличия чувственного компонента и любви. По мнению женщин двух групп, отец принимает активное участие в воспитании ребенка, проявляет интерес к его успехам, беспокоится по поводу возможных неудач, старается вступать в эмоциональный контакт с ребенком, общается с ним. Мужчины также стараются проявлять мужские качества, возлагая на себя ответственность за себя и за близких. При этом отец не только олицетворяет защиту и покровительство, он ориентирован на эмоциональное благополучие, создание благоприятной атмосферы, характеризующейся взаимным доверием, уважением и открытым доброжелательным общением.

Выводы. В заключении необходимо отметить, что по структуре и содержанию представления об отцовстве у мужчин, состоящих и не состоящих в браке, являются довольно простыми, в то время как у женщин со вступлением в брак, представления об отцовстве усложняются, становятся глубже и чувственнее.

Перспектива дальнейших исследований в данном направлении видится в выявлении факторов-конструктов, образующих иерархическую структуру представлений у мужчин и женщин с разным стажем супружества.

\section{СПИСОК ССЫЛОК}

Андреева, Г. М. (2001). Социиальная психология. Москва: Аспект Пресс.

Борисенко, Ю. В. (2007). Психология отиовства. Обнинск: ИГ-СОЦИН.

Кон, И. С. (2003) Ребенок и общество. Москва: Академия.

Московичи, С. (2007). Социальная психология. Санкт-Петербург: Питер.

Окулич, Н. А. (2015). Как стать успешным родителем. Минск: ИВЦ Минфина

Павлов, И. В. (2014) Взаимосвязь образа отца и образа «я» у юношей и девушек из полных и неполных семей. Вестник Барановичского государственного университета, 2, 63-67.

\section{REFERENCES}

Andreeva, G. M. (2001). Social'naya psihologiya. Moskva: Aspekt Press. [in Russian]. Borisenko, Yu. V. (2007). Psihologiya otcovstva. Obninsk: IG-SOCIN. [in Russian].

Kon, I. S. (2003) Rebenok i obshchestvo. Moskva: Akademiya. [in Russian].

Moskovichi, S. (2007). Social'naya psihologiya. Sankt-Peterburg: Piter. [in Russian].

Okulich, N. A. (2015). Kak stat' uspeshnym roditelem. Minsk: IVC Minfina [in Russian].

Pavlov, I. V. (2014) Vzaimosvyaz' obraza otca i obraza «ya» u yunoshej i devushek iz polnyh i nepolnyh semej. Vestnik Baranovichskogo gosudarstvennogo universiteta, 2, 63-67. [in Russian]. 


\section{СОЦІАЛЬНІ У ЯВЛЕННЯ ПРО БАТЬКІВСТВО У ЧОЛОВІКІВ І ЖІНОК, ЩО ПЕРЕБУВАЮТЬ ТА НЕ ПЕРЕБУВАЮТЬ У ШЛЮБІ}

Наталія Билінська

кандидат психологічних наук, доцент, завідуюча кафедрою психології

Брестського державного університету імені О. С. Пушкіна, м. Брест (Республіка Білорусь)

Анотація У статті обговорюється феномен «батьківство» в контексті наукових $i$ життєвих уявлень, викладені результати вивчення структури і змісту уявлень про цей феномен, які існують у свідомості чоловіків і жінок. Порівняльний аналіз структури з змісту когнітивних міркувань показав, щзо в змісті уявлень про батьківство у чоловіків $і$ жінок, які перебувають чи не перебувають у шлюбі, є загальні та специффічні дескриптори. Загальні свідчать про єдність розумінь, специфічні - вказують на відмінності в уявленнях про батьківство: вони значною мірою є унікальними та індивідуальними для кожної людини. Встановлено, шуо структура $і$ зміст уявлень про батьківство має якісні і кількісні характеристики, які різняться у представників жіночої $і$ чоловічої статі. У одружених $і$ неодружених чоловіків уявлення про батьківство, за своєю структурою $і$ змістом, є досить простими, у той час як у жінок факт утворення сім' детермінує перегляд системи ставлень. Уявлення про батьківство у одружених жінок стають більи глибокими та емоційно забарвленими.

Ключові слова: батько, батькіство, сім'я, соціальні уявлення, життєва свідомість, факторний аналіз, фактор, конструкт.

\section{SOCIAL ATTITUDES TOWARDS THE FATHERHOOD IN NARRATIVES OF MARRIED AND UNMARRIED PEOPLE}

Nataliia Bylinskaya,

Candidate of Psychological Sciences, Associate Professor The head of the department of Psychology at the Brest State A.S. Pushkin University Brest, Belarus http://orcid.org/0000-0002-2545-5592

Abstract: The issue of social attitudes towards the "fatherhood" is discussed in the article. We studied the structure and content of men and women's ideas about fatherhood according to their matrimonial status. A comparative analysis of their narratives showed that content of ideas of married and unmarried people regarding the parenting had some common and specific descriptors. The first ones confirmed the commonality of understanding paternity, whereas the specific ones indicated differences in cognitive and emotional representations of phenomenon: they were largely unique and had more personal features. It has been found that the structure and content of ideas about the fatherhood had qualitative and quantitative gender-related features. In terms of structure and content, the attitudes of both married and unmarried men were quite similar and simple, whereas women's concept of fatherhood became more complicated, deeper and more sensitive when they got married.

According to the opinion of married women, a man not only provides material wealth to the family. He focuses on family, emotional well-being, on creating a favorable atmosphere with mutual trust and respect, open and friendly communication. The content of factors in the attitudes of married and unmarried men was contraversial. On the one hand, they revealed men's desire to show love forthe child, take care of him and whole family, their understanding the responsibility that man should assume as the head of the family. On the other hand, men associated the fulfillment of the educational function of the father with the expectation of difficulties in interacting with the child and the need to spend time on decent material support for the family. That's why the prospect of further research in this direction is seen in the study of the structure and content of social ideas about paternity of married men and married women with different lengths of marriage.

Key words: father, fatherhood, family, social representations, common attitudes, factor analysis, factor, construct. 